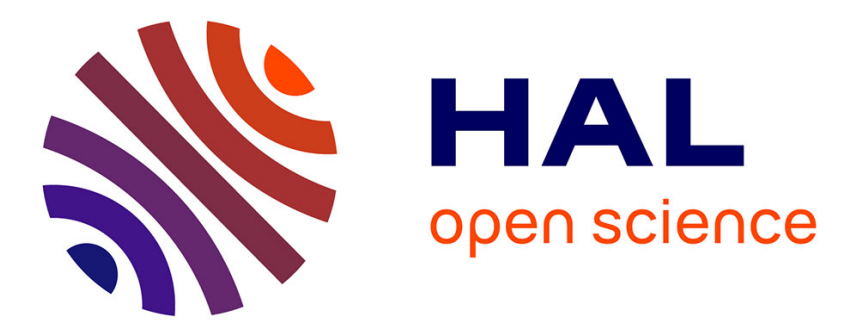

\title{
Efficacy of tigecycline vs. imipenem in the treatment of experimental murine pneumonia
}

\author{
C. Pichardo, M. E. Pachón-Ibañez, F. Docobo-Perez, R. López-Rojas, M. E. \\ Jiménez-Mejías, A. Garcia-Curiel, J. Pachon
}

\section{To cite this version:}

C. Pichardo, M. E. Pachón-Ibañez, F. Docobo-Perez, R. López-Rojas, M. E. Jiménez-Mejías, et al.. Efficacy of tigecycline vs. imipenem in the treatment of experimental murine pneumonia. European Journal of Clinical Microbiology and Infectious Diseases, 2010, 29 (5), pp.527-531. 10.1007/s10096010-0890-6 . hal-00569394

\section{HAL Id: hal-00569394 \\ https://hal.science/hal-00569394}

Submitted on 25 Feb 2011

HAL is a multi-disciplinary open access archive for the deposit and dissemination of scientific research documents, whether they are published or not. The documents may come from teaching and research institutions in France or abroad, or from public or private research centers.
L'archive ouverte pluridisciplinaire HAL, est destinée au dépôt et à la diffusion de documents scientifiques de niveau recherche, publiés ou non, émanant des établissements d'enseignement et de recherche français ou étrangers, des laboratoires publics ou privés. 


\title{
Efficacy of tigecycline vs. imipenem in the treatment of experimental Acinetobacter baumannii murine pneumonia
}

\author{
C. Pichardo • M. E. Pachón-Ibañez • F. Docobo-Perez • \\ R. López-Rojas • M. E. Jiménez-Mejías • \\ A. Garcia-Curiel • J. Pachon
}

Received: 31 July 2009 /Accepted: 1 February 2010 /Published online: 25 February 2010

(C) Springer-Verlag 2010

\begin{abstract}
The in vivo activity of tigecycline was evaluated in an experimental pneumonia model (C57BL/6 mice) by Acinetobacter baumannii. Two clinical strains were used: minimum inhibitory concentrations (MICs) of imipenem and tigecycline 1 and $2 \mu \mathrm{g} / \mathrm{mL}$ (imipenem-susceptible, IPM-S), and 8 and $2 \mu \mathrm{g} / \mathrm{mL}$ (imipenem-intermediate, IPMI), respectively. For imipenem $(30 \mathrm{mg} / \mathrm{Kg}), \Delta \mathrm{T} / \mathrm{CMI}$ (h) were 1.04 and 0.51 for IPM-S and IPM-I, respectively. For tigecycline $(5 \mathrm{mg} / \mathrm{Kg})$, the area under the concentrationtime curve (AUC)/ $\mathrm{MIC}_{0-24 \mathrm{~h}}$ (serum and lung) were 9.24 and 4.37 (for the two strains), respectively. In the efficacy experiments with the IPM-S, imipenem $(\log \mathrm{CFU} / \mathrm{g} 3.59 \pm$ $0.78, p=0.006)$ and tigecycline $(2.82 \pm 1.2, p=0.054)$ decreased the bacterial counts in lungs with respect to its controls; with the IPM-I, both imipenem $(1.21 \pm 0.52, p=$ $0.002)$ and tigecycline $(3.21 \pm 0.28, p=0.035)$ decreased the bacterial counts with respect to the controls. In the survival experiments, with the IPM-S, the mortality was the same in the control (67\%) and in the tigecycline (77\%) groups, and imipenem reduced it $(21 \%, p=0.025)$; with the IPM-I, the mortality was the same in the control $(87 \%)$ and in the
\end{abstract}

C. Pichardo $(\triangle) \cdot$ M. E. Pachón-Ibañez $\cdot$ F. Docobo-Perez

R. López-Rojas · M. E. Jiménez-Mejías • A. Garcia-Curiel •

J. Pachon

Instituto de Biomedicina de Sevilla, Hospital Universitario

Virgen del Rocío/CSIC/Universidad de Sevilla,

Avda. Manuel Siurot s/n,

41013 Seville, Spain

e-mail: cristina.pichardo.exts@juntadeandalucia.es

C. Pichardo $\cdot$ M. E. Pachón-Ibañez $\cdot$ F. Docobo-Perez $\cdot$

R. López-Rojas · M. E. Jiménez-Mejías · A. Garcia-Curiel •

J. Pachon

Spanish Network for Research in Infectious Diseases

(REIPI-ISCIII-RD06/0008), Instituto de Salud Carlos III,

Madrid, Spain tigecycline $(85 \%)$ groups, and imipenem $(0 \%)$ reduced it $(p<0.001)$. In summary, the present study shows that tigecycline is less efficacious than imipenem in the treatment of experimental $A$. baumannii pneumonia caused by IPM-S and IPM-I strains.

\section{Introduction}

Acinetobacter baumannii is a common nosocomial pathogen, especially in intensive care units, causing a great number of clinical conditions, being pneumonia or bacteremia the more frequent infections $[1,2]$. In the last several years, multi-resistant strains are frequent $[1,3]$ and, with the recent reports of outbreaks of colistin-resistant $A$. baumannii isolates[4], new antimicrobial agents have been searched.

Recent studies have shown that tigecycline exhibits potent activity against organisms isolated from hospitalized patients, including multidrug-resistant nonfermentative gram-negative bacilli, among others [5, 6]. Specifically, tigecycline was in vitro-active against $A$. baumannii strains, including those resistant to imipenem, being bacteriostatic in the time-kill studies [7]. In the treatment of multiresistant $A$. baumannii ventilator-associated pneumonia (VAP), three patients were cured with tigecycline in monotherapy and 15 out of 19 patients $(78.9 \%)$ were cured when treated with tigecycline plus imipenem and/or colistin [8]. Data from more studies are needed before tigecycline can be recommended for the treatment of Acinetobacter infections.

The purpose of this study is to compare the efficacy of tigecycline and imipenem in a murine pneumonia model caused by $A$. baumannii strains susceptible and intermediate to imipenem. 


\section{Materials and methods}

We used two A. baumannii strains collected from blood cultures, corresponding to the more prevalent clones isolated in our hospital: imipenem-susceptible strain (IPM-S, 953, minimum inhibitory concentration [MIC] imipenem $=1 \mathrm{mg} / \mathrm{L}$, tigecycline $=2 \mathrm{mg} / \mathrm{L}$ ), and imipenemintermediate strain (IPM-I, 1514, MIC imipenem $=8 \mathrm{mg} / \mathrm{L}$, tigecycline $=2 \mathrm{mg} / \mathrm{L})$.

Imipenem (laboratory standard powder) and imipenem plus cilastatin (IPM) were obtained from Merck Sharp \& Dohme (Madrid, Spain) for the in vitro and the in vivo experiments, respectively, and tigecycline (TGC) from Wyeth-Ayerst (Pearl River, NY, USA).

The animals used were immunocompetent C57BL/6 female mice weighing 14-16 g (University of Seville's facility) and had a sanitary status of murine pathogen-free (MPF).

\section{Drug pharmacokinetics}

The plasma levels of imipenem were determined after the administration of a single intramuscular (im) dose of $30 \mathrm{mg} / \mathrm{Kg}$. The plasma and lung (homogenate) levels of tigecycline were determined after the administration of a single subcutaneal (sc) dose of $5 \mathrm{mg} / \mathrm{Kg}$. Blood and lungs were extracted from three anesthetized mice per time-point. The total plasmatic drug concentrations and the total drug concentrations in the lung were measured for triplicate by the bioassay method, using Micrococcus luteus ATCC 9341 for imipenem and Bacillus cereus ATCC 9634 for tigecycline as the indicator strains. The intraday and interday variation of the assays were $2.6 \% \pm 2.4 \%$ and $3.2 \% \pm 1.9 \%$ for imipenem, and $3.5 \% \pm 2.6 \%$ and $4.5 \% \pm 1.1 \%$ for tigecycline; the linearity $\left(r^{2}\right)$ of the assay was $0.91 \pm 0.02$ and $0.92 \pm 0.32$, respectively, and the lower limits of detection were 0.01 and $0.1 \mathrm{mg} / \mathrm{L}$. The maximum plasma concentration $\left(C_{\max }, \mathrm{mg} / \mathrm{L}\right)$ and terminal half-life $\left(t_{1 / 2}, \mathrm{~h}\right)$ were calculated. The time during which the plasma concentration remained above the MIC $(\Delta \mathrm{T} / \mathrm{MIC}, \mathrm{h})$ was estimated by extrapolation from the regression line of plasma elimination.

Experimental pneumonia model in mice

A modification of the Esposito and Pennington model performed by our group [9] was used to produce pneumonia. The animals were inoculated with $50 \mu$ l of the $A$. baumannii bacterial suspension, with a final inoculum size of approximately $10^{8} \mathrm{CFU} / \mathrm{mL}$. The treatment was commenced at $4 \mathrm{~h}$ after the inoculation, grouping the mice in each of the following treatment groups over a period of $72 \mathrm{~h}$ : (a) controls, no treatment; (b) tigecycline, $10 \mathrm{mg} / \mathrm{Kg} /$ d/sc, b.i.d.; and (c) imipenem, $120 \mathrm{mg} / \mathrm{Kg} / \mathrm{d} / \mathrm{im}$, t.i.d. (a quarter of the total dose at 8:00 and 14:00 h, and the half of the total dose at 20:00 h). Two types of experiments were performed: survival and bacterial clearance from lung studies.

\section{Survival experiments}

Because in this model the mortality in the control group is near $100 \%$ at $72 \mathrm{~h}$, the influence on the mortality of the different treatments was evaluated in this period, in groups of 15 mice.

\section{Efficacy experiments}

To evaluate the efficacy of antimicrobials in the clearance of bacteria from lungs, efficacy experiments were performed. Groups of five mice were sacrificed at $4 \mathrm{~h}$ after the infection, before the beginning of treatments (control groups), and groups of five mice were sacrificed every $24 \mathrm{~h}, 4 \mathrm{~h}$ after the last dose in the case of IPM and $12 \mathrm{~h}$ after the last dose in the case of tigecycline (treatment groups). At these time-points, the surviving mice were sacrificed and thoracotomy was carried out; the lungs were removed, weighed, and processed for quantitative cultures. The results were expressed as the $\log _{10} \mathrm{CFU} / \mathrm{g}$ of tissue.

In order to confirm that imipenem and tigecycline were not toxic to the animals, groups of ten non-infected mice were each given the antibiotics for $72 \mathrm{~h}$. The use of the experimental pneumonia model was approved by the Ethics Committee of the Hospital Universitario Virgen del Rocío, Sevilla, Spain.

\section{Statistical analysis}

The numbers of surviving animals were evaluated with Fisher's exact test. The CFU/g of lung tissue was analyzed using the Kruskal-Wallis test. The SPSS v13.0 statistical package (SPSS Inc., Chicago, IL, USA) was used. A $p$ value $<0.05$ was considered to be significant.

\section{Results and discussion}

The pharmacokinetic/pharmacodynamic parameters of each antimicrobial drug $\left(C_{\max }, t_{1 / 2}, \mathrm{AUC}, \Delta \mathrm{T} / \mathrm{MIC}\right.$, and $\mathrm{AUC}_{0-24 \mathrm{~h}} /$ MIC) are shown in Table 1.

In the survival experiments (Table 2), with both strains IPM-I and IPM-S, only imipenem reduces the mortality with respect to the control groups ( 0 and $21 \%$ in the imipenem groups and 87 and $67 \%$ in the controls, respectively, $p \leq 0.025)$; imipenem was better than tigecycline in both groups $(p \leq 0.007)$. 
Table 1 Pharmacokinetic/pharmacodynamic parameters

\begin{tabular}{|c|c|c|c|c|c|c|c|}
\hline & \multirow[t]{2}{*}{$C_{\max }$} & \multirow[t]{2}{*}{$t_{1 / 2}(\mathrm{~h})$} & \multirow[t]{2}{*}{ AUC (mg.h/L) } & \multicolumn{2}{|l|}{$\mathrm{AUC} / \mathrm{MIC}_{0-24 \mathrm{~h}}$} & \multicolumn{2}{|l|}{$\Delta \mathrm{T} / \mathrm{MIC}(\mathrm{h})$} \\
\hline & & & & Strain 1514 IPM-I & $\begin{array}{l}\text { Strain } 953 \\
\text { IPM-S }\end{array}$ & $\begin{array}{l}\text { Strain } 1514 \\
\text { IPM-I }\end{array}$ & $\begin{array}{l}\text { Strain } 953 \\
\text { IPM-S }\end{array}$ \\
\hline Tigecycline (serum) $5 \mathrm{mg} / \mathrm{Kg}$ & $1.92 \mathrm{mg} / \mathrm{L}$ & 2.33 & 9.24 & 9.24 & 9.24 & 1.70 & 1.70 \\
\hline Tigecycline (lung) $5 \mathrm{mg} / \mathrm{Kg}$ & $8.29 \mu \mathrm{g} / \mathrm{g}$ & 0.23 & 4.37 & 4.37 & 4.37 & 0.97 & 0.97 \\
\hline Imipenem (serum) $30 \mathrm{mg} / \mathrm{Kg}$ & $16.9 \mathrm{mg} / \mathrm{L}$ & 0.15 & 8.25 & 4.12 & 33 & 0.51 & 1.04 \\
\hline
\end{tabular}

$C_{\max }$ : maximal drug concentration; $t_{1 / 2}$ : half-life; AUC: area under the concentration-time curve; $\mathrm{AUC} / \mathrm{MIC}_{0-24} \mathrm{~h}$ : area under the concentrationtime curve at $24 \mathrm{~h}$ to the MIC; $\Delta \mathrm{T} / \mathrm{MIC}$ : the time that a drug concentration remains above the MIC

In the bacterial clearance from the lungs experiments (Fig. 1), with the IPM-I strain, for the imipenem-treated group, there was a decrease of the bacterial counts from controls $(p=0.002)$. In the tigecycline-treated group, the treatment cleared the lungs compared to the control group $(p=0.035)$. With the IPM-S strain, in the imipenem-treated group, there was a decrease of the bacterial counts $(p=$ 0.006) and in the tigecycline-treated group, the bacterial lung concentration decreased to $2.82 \log \mathrm{CFU} / \mathrm{g}(p=0.054)$.

These results show that, in general, imipenem is more active than tigecycline in this experimental pneumonia model caused by $A$. baumannii with the doses examined. Tigecycline decreased the bacterial count in the lung for the strain intermediate to imipenem with respect to the controls. However, in the in vivo experiments performed with the strains susceptible and intermediate to imipenem, imipenem was better than tigecycline regarding the mortality and clearance of bacteria from the lungs.

Different studies in experimental $A$. baumannii pneumonia models had shown that imipenem was the most active antimicrobial, including infections caused by susceptible and intermediate strains $[9,10]$. Different works showed the high in vitro activity of tigecycline from multi-resistant pathogens, including A. baumannii [5, 6], which is of particular importance because of the high frequency of multi-resistant strains [1, 3], with a high number of strains only susceptible to colistin $[1,11,12]$ or the appearance of pan-resistant $A$. baumannii isolates $[13,14]$. In a previous in vitro study on the activity of imipenem and tigecycline against 49 isolates of $A$. baumannii, the $\mathrm{MIC}_{90}$ values were 128 and $2 \mathrm{mg} / \mathrm{L}$, respectively; however, in the time-kill studies, tigecycline was bacteriostatic [7]. The limited efficacy of tigecycline in the experimental pneumonia model may be explained by the in vitro bacteriostatic instead of bactericidal activity against $A$. baumannii.

Tigecycline has high penetration in tissues $[15,16]$; thus, we found a serum and lung $C_{\max }$ of $1.92 \mathrm{mg} / \mathrm{L}$ and $8.29 \mu \mathrm{g} /$ $\mathrm{g}$, respectively. These figures are higher than those found in humans after doses of 50 and $100 \mathrm{mg}$, which show serum $C_{\max }$ values of 0.38 and $0.91 \mathrm{mg} / \mathrm{L}[15,17]$, respectively, and the mean and median concentration values of tigecycline in the lungs after $100 \mathrm{mg}$ were 0.50 and $0.31 \mu \mathrm{g} / \mathrm{g}$ (range: $0.11-1.89 \mu \mathrm{g} / \mathrm{g}$ ) [18]. There are no definitive data regarding the pharmacodynamic variables predicting the in vivo efficacy of tigecycline. Several studies had addressed this issue, both in clinical trials and in experimental models of infection $[15,16]$. Some authors suggest that, although tetracyclines do not exhibit concentration-dependent killing, if the antimicrobial agent has a moderate to prolonged postantibiotic effect (PAE), the time of exposure is less important and the AUC/MIC ratio is the best pharmacokinetic/pharmacodynamic parameter correlating with the therapeutic efficacy of these drugs [19]. Data obtained in animal models $[17,20]$ suggest that tigecycline activity

Table 2 Survival study using three strains with different susceptibilities to imipenem

\begin{tabular}{|c|c|c|c|c|c|c|}
\hline & \multicolumn{3}{|c|}{ Strain 1514 (IPM-I) } & \multicolumn{3}{|c|}{ Strain 953 (IPM-S) } \\
\hline & $n$ & $n$ died & $\%$ & $n$ & $n$ died & $\%$ \\
\hline Controls & 15 & 13 & 87 & 15 & 10 & 67 \\
\hline Imipenem, $120 \mathrm{mg} / \mathrm{Kg} / \mathrm{d} / \mathrm{im}$ & 15 & 0 & $0^{\mathrm{a}}$ & 14 & 3 & $21^{\mathrm{b}}$ \\
\hline Tigecycline, $10 \mathrm{mg} / \mathrm{Kg} / \mathrm{d} / \mathrm{sc}$ & 13 & 11 & 85 & 13 & 10 & 77 \\
\hline
\end{tabular}

IPM: imipenem, I: intermediate, S: susceptible

${ }^{\mathrm{a}} p<0.001$ compared to the controls and tigecycline.

${ }^{\mathrm{b}} p=0.025$ and $p=0.007$ compared to the controls and tigecycline, respectively 


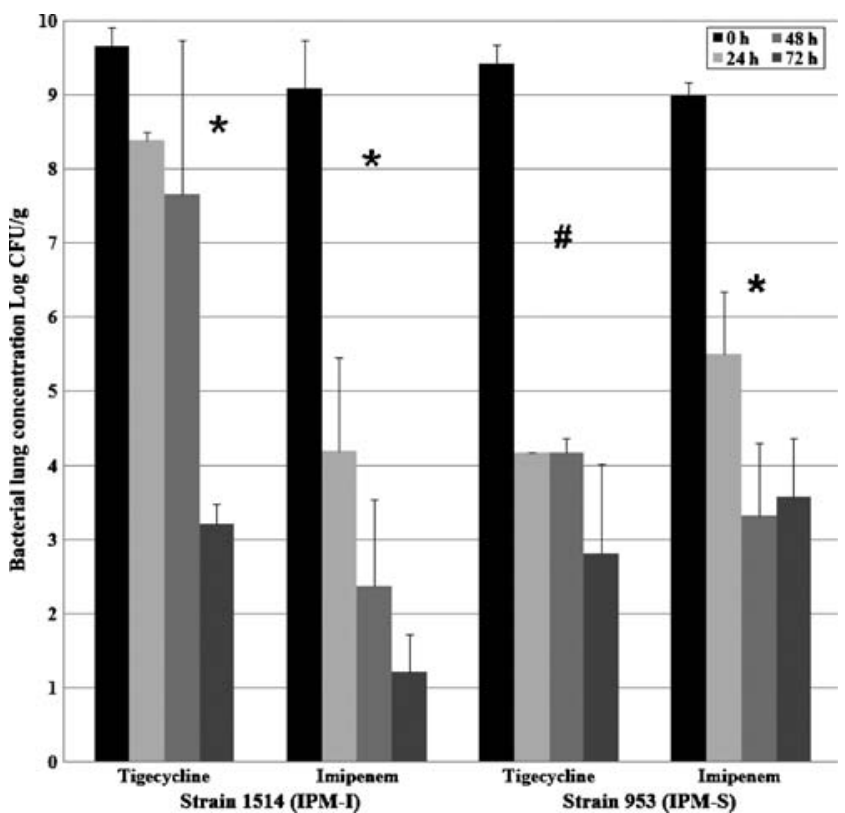

Fig. 1 Bacterial clearance from lung tissue using two strains with different susceptibilities to imipenem (treatment during a period of $72 \mathrm{~h}$ ). Values are expressed as mean \pm standard deviation (SD) (log $\mathrm{CFU} / \mathrm{g}) .{ }^{*} p<0.05,{ }^{\#} p=0.054$

depends on the time above the MIC and on the AUC/MIC. On the other hand, the relationship between the AUC, MIC, and the microbiologic results in clinical trials in complicated skin and soft tissue infections were revised recently [21, 22], showing that an AUC/MIC ratio between 6.96 and 12.3 was necessary for a good clinical and microbiological response, with the predominant pathogens being Staphylococcus aureus and Streptococcus spp. However, although in our experiments the serum AUC/MIC of tigecycline was 9.24, we did not obtain the same favorable results in the pneumonia by $A$. baumannii.

The clinical information on the relevance of tigecycline as an antimicrobial agent against $A$. baumannii is scarce. A clinical case of septic shock due to a multidrug-resistant $A$. baumannii strain in a patient with intra-abdominal abscess after acute pancreatitis, with failure during treatment with colistin plus meropenem, cured after the addition of tigecycline [23]. In the treatment of multi-resistant $A$. baumannii VAP in a recent study [8], three patients were cured with tigecycline in monotherapy and 15 out of 19 patients $(78.9 \%)$ cured when treated with tigecycline plus imipenem and/or colistin. In other study, only two out of five patients with $A$. baumannii VAP were cured with tigecycline in monotherapy or in combination [24].

Peleg et al. [25] show the first clinical description of bloodstream infection caused by tigecycline-nonsusceptible A. baumannii. In their work, two patients developed breakthrough $A$. baumannii bacteraemia while receiving tigecycline for other indications. The MICs of tigecycline for these strains were 4 and $16 \mathrm{mg} / \mathrm{L}$, respectively, and the resistance appears to be at least partly attributable to an efflux pump mechanism, since the exposure to an efflux pump inhibitor diminished the MIC of tigecycline 4 to $1 \mathrm{mg} / \mathrm{L}$ and from 16 to $4 \mathrm{mg} / \mathrm{L}$, respectively. The authors conclude that, given the facility of A. baumannii to acquire resistance to other antimicrobials, exposure to sub-therapeutic levels of tigecycline for even short periods of time may promote the rapid emergence of tigecycline resistance. In this sense, a recent multicenter Spanish study obtained an $\mathrm{MIC}_{90}$ of tigecycline for $A$. baumannii of $8 \mathrm{mg} / \mathrm{L}$ [26], which is higher than that found previously by us [7].

The results of the present experimental study and those from the clinical experience pointed to the necessity of evaluating tigecycline combined with other antimicrobials when treating severe A. baumannii infections. Thus, in a model of $A$. baumannii experimental murine pneumonia caused by imipenem-susceptible strains [9], the treatment with other tetracyclines, such as doxycycline plus amikacin, was as efficacious as imipenem in reducing the mortality and the clearance of bacteria from the lungs, this combination being synergic in vitro.

However, in an in vitro study using time-kill curves [27], the possible synergy of tigecycline plus amikacin, meropenem, imipenem, ciprofloxacin, levofloxacin, ampicillin-sulbactam, and rifampin has been evaluated against A. baumannii strains intermediate or resistant to carbapenems $\left(\mathrm{MIC}_{90}\right.$ of tigecycline of $2 \mathrm{mg} / \mathrm{L}$ ), showing indifference for tigecycline in combination with these antimicrobials. Also, concentration escalation studies demonstrate that tigecycline may need to approach serum concentrations higher than those currently achieved to treat multidrug-resistant $A$. baumannii. In the same way, using checkerboard testing, tigecycline synergy was observed in only 1 of 5 strains when combined with cefepime or amikacin, and no synergy was shown with the combination of tigecycline with amoxicillin/cavulanate, piperacillin/ tazobactam, ceftriaxone, ceftazidime, imipenem, meropenem, aztreonam, trimethoprim/sulfamethoxazole, or ciprofloxacin [28].

In summary, the present study, taking into account the limitations of the small size of the groups in the efficacy experiments, shows that tigecycline in monotherapy is less efficacious than imipenem in the treatment of experimental A. baumannii pneumonia caused by susceptible or intermediate to imipenem strains. However, due to its in vitro activity against multi-resistant $A$. baumannii, the high mortality of severe infections caused by this bacterium, such as VAP and bacteremia, and the paucity of therapeutic alternatives for these severe infections, new in vivo studies are needed to evaluate its efficacy in combination with other antimicrobials. 
Acknowledgments This work was partly supported by a grant from the Wyeth-Ayerst Research (Pearl River, NY, USA). The authors declare no conflict of interest with respect to this article.

\section{References}

1. Cisneros JM, Reyes MJ, Pachón J, Becerril B, Caballero FJ, García-Garmendía JL, Ortiz C, Cobacho AR (1996) Bacteremia due to Acinetobacter baumannii: epidemiology, clinical findings, and prognostic features. Clin Infect Dis 22:1026-1032

2. Garnacho-Montero J, Ortiz-Leyba C, Jiménez-Jiménez FJ, Barrero-Almodóvar AE, García-Garmendia JL, Bernabeu-Wittell M, Gallego-Lara SL, Madrazo-Osuna J (2003) Treatment of multidrug-resistant Acinetobacter baumannii ventilator-associated pneumonia (VAP) with intravenous colistin: a comparison with imipenem-susceptible VAP. Clin Infect Dis 36:1111-1118

3. Fernández-Cuenca F, Pascual A, Ribera A, Vila J, Bou G, Cisneros JM, Rodríguez-Baño J, Pachón J, Martínez-Martínez L; Grupo de Estudio de Infección Hospitalaria (2004) Diversidad clonal y sensibilidad a los antimicrobianos de Acinetobacter baumannii aislados en hospitales españoles. Estudio multicéntrico nacional: proyecto GEIH-Ab2000. Enferm Infecc Microbiol Clin 22(5):267-271

4. Vila J, Pachón J (2008) Therapeutic options for Acinetobacter baumannii infections. Expert Opin Pharmacother 9(4):587-599

5. Bouchillon SK, Hoban DJ, Johnson BM, Johnson JL, Hsiung A, Dowzicky MJ; Tigecycline Evaluation and Surveillance Trial (TEST) Group (2005) In vitro activity of tigecycline against 3989 gram-negative and gram-positive clinical isolates from the United States Tigecycline Evaluation and Surveillance Trial (TEST Program; 2004). Diagn Microbiol Infect Dis 52(3):173-179

6. Fritsche TR, Sader HS, Stilwell MG, Dowzicky MJ, Jones RN (2005) Potency and spectrum of tigecycline tested against an international collection of bacterial pathogens associated with skin and soft tissue infections (2000-2004). Diagn Microbiol Infect Dis 52(3):195-201

7. Pachón-Ibáñez ME, Jiménez-Mejías ME, Pichardo C, Llanos AC, Pachón J (2004) Activity of tigecycline (GAR-936) against Acinetobacter baumannii strains, including those resistant to imipenem. Antimicrob Agents Chemother 48:4479-4481

8. Schafer JJ, Goff DA, Stevenson KB, Mangino JE (2007) Early experience with tigecycline for ventilator-associated pneumonia and bacteremia caused by multidrug-resistant Acinetobacter baumannii. Pharmacotherapy 27(7):980-987

9. Rodríguez-Hernández MJ, Pachón J, Pichardo C, Cuberos L, Ibáñez-Martínez J, García-Curiel A, Caballero FJ, Moreno I, Jiménez-Mejías ME (2000) Imipenem, doxycycline and amikacin in monotherapy and in combination in Acinetobacter baumannii experimental pneumonia. J Antimicrob Chemother 45:493-501

10. Wolff M, Joly-Guillou ML, Farinotti R, Carbon C (1999) In vivo efficacies of combinations of $\beta$-lactams, $\beta$-lactamase inhibitors, and rifampin against Acinetobacter baumannii in a mouse pneumonia model. Antimicrob Agents Chemother 43:1406-1411

11. Bergogne-Bérézin E, Towner KJ (1996) Acinetobacter spp. as nosocomial pathogens: microbiological, clinical, and epidemiological features. Clin Microbiol Rev 9:148-165

12. Bou G, Cerveró G, Domínguez MA, Quereda C, Martínez-Beltrán J (2000) Characterization of a nosocomial outbreak caused by a multiresistant Acinetobacter baumannii strain with a carbapenemhydrolyzing enzyme: high-level carbapenem resistance in $A$. baumannii is not due solely to the presence of $\beta$-lactamases. $\mathrm{J}$ Clin Microbiol 38:3299-3305

13. Henwood CJ, Gatward T, Warner M, James D, Stockdale MW, Spence RP, Towner KJ, Livermore DM, Woodford N (2002) Antibiotic resistance among clinical isolates of Acinetobacter in the UK, and in vitro evaluation of tigecycline (GAR-936). J Antimicrob Chemother 49:479-487

14. Urban C, Mariano N, Rahal JJ, Tay E, Ponio C, Koprivnjak T, Weiss J (2000) Polymyxin B-resistant Acinetobacter baumannii clinical isolate susceptible to recombinant $\mathrm{BPI}_{21}$ and cecropin $\mathrm{P} 1$. Antimicrob Agents Chemother 45:994-995

15. Meagher AK, Ambrose PG, Grasela TH, Ellis-Grosse EJ (2005) Pharmacokinetic/pharmacodynamic profile for tigecycline-a new glycylcycline antimicrobial agent. Diagn Microbiol Infect Dis 52 (3):165-171

16. Muralidharan G, Micalizzi M, Speth J, Raible D, Troy S (2005) Pharmacokinetics of tigecycline after single and multiple doses in healthy subjects. Antimicrob Agents Chemother 49(1):220-229

17. Rubinstein E, Vaughan D (2005) Tigecycline: a novel glycylcycline. Drugs 65(10):1317-1336

18. Rodvold KA, Gotfried MH, Cwik M, Korth-Bradley JM, Dukart G, Ellis-Grosse EJ (2006) Serum, tissue and body fluid concentrations of tigecycline after a single $100 \mathrm{mg}$ dose. J Antimicrob Chemother 58(6):1221-1229

19. Craig WA (1998) Pharmacokinetic/pharmacodynamic parameters: rationale for antibacterial dosing of mice and men. Clin Infect Dis 26:1-12

20. van Ogtrop ML, Andes D, Stamstad TJ, Conklin B, Weiss WJ, Craig WA, Vesga O (2000) In vivo pharmacodynamic activities of two glycylcyclines (GAR-936 and WAY 152,288) against various gram-positive and gram-negative bacteria. Antimicrob Agents Chemother 44(4):943-949

21. Agwuh KN, MacGowan A (2006) Pharmacokinetics and pharmacodynamics of the tetracyclines including glycylcyclines. J Antimicrob Chemother 58(2):256-265

22. Doan TL, Fung HB, Mehta D, Riska PF (2006) Tigecycline: a glycylcycline antimicrobial agent. Clin Ther 28(8):1079-1106, Review

23. Taccone FS, Rodriguez-Villalobos H, De Backer D, De Moor V, Deviere J, Vincent JL, Jacobs F (2006) Successful treatment of septic shock due to pan-resistant Acinetobacter baumannii using combined antimicrobial therapy including tigecycline. Eur J Clin Microbiol Infect Dis 25:257-260

24. Anthony KB, Fishman NO, Linkin DR, Gasink LB, Edelstein PH, Lautenbach E (2008) Clinical and microbiological outcomes of serious infections with multidrug-resistant gram-negative organisms treated with tigecycline. Clin Infect Dis 46:567-570

25. Peleg AY, Potoski BA, Rea R, Adams J, Sethi J, Capitano B, Husain S, Kwak EJ, Bhat SV, Paterson DL (2007) Acinetobacter baumannii bloodstream infection while receiving tigecycline: a cautionary report. J Antimicrob Chemother 59(1):128-131

26. Betriu C, Rodriguez-Avial I, Gómez M, Culebras E, López F, Alvarez J, Picazo JJ; Spanish Tigecycline Group (2006) Antimicrobial activity of tigecycline against clinical isolates from Spanish medical centers. Second multicenter study. Diagn Microbiol Infect Dis 56(4):437-444

27. Scheetz MH, Qi C, Warren JR, Postelnick MJ, Zembower T, Obias A, Noskin GA (2007) In vitro activities of various antimicrobials alone and in combination with tigecycline against carbapenem-intermediate or -resistant Acinetobacter baumannii. Antimicrob Agents Chemother 51(5):1621-1626

28. Vouillamoz J, Moreillon P, Giddey M, Entenza JM (2008) In vitro activities of tigecycline combined with other antimicrobials against multiresistant gram-positive and gram-negative pathogens. J Antimicrob Chemother 61:371-374 